\title{
Determining Transmission Coefficient of Propagating Solitary Wave over Trapezoidal Breakwater and Parametric Studies on Different Influential Factors
}

\author{
Amin Rahimzadeh, Parviz Ghadimi, Mohammad A. Feizi Chekab, \\ and Mohammad H. Jabbari \\ Department of Marine Technology, Amirkabir University of Technology, Hafez Avenue, No. 424, P.O. Box 15875-4413, Tehran, Iran \\ Correspondence should be addressed to Parviz Ghadimi; pghadimi@aut.ac.ir
}

Received 1 February 2014; Accepted 17 March 2014; Published 10 April 2014

Academic Editors: P. Dineva, J. S. Go, and A. Szekrenyes

Copyright (C) 2014 Amin Rahimzadeh et al. This is an open access article distributed under the Creative Commons Attribution License, which permits unrestricted use, distribution, and reproduction in any medium, provided the original work is properly cited.

\begin{abstract}
The objective of this study is to numerically investigate transmission coefficient of submerged trapezoidal breakwater of various configurations subjected to solitary waves. Boussinesq equations of Madsen and Sorensen are applied as governing equations for simulation purposes. Discretization of governing equations is accomplished using Galerkin finite element method and AdamsBashforth-Moulton predictor-corrector method is considered for time integration. In order to obtain transmission coefficients, two gauges are considered before and after the submerged breakwater to record initial and transmitted wave heights, respectively. To examine the effect of configuration of breakwaters on their transmission coefficients, submergence ratio and crest width ratio are defined and analyzed. Different submergence ratios and various crest width ratios are considered. Computed results indicate how transmission coefficient decreases with the increase over different ranges of crest width ratio, for all values of submergence ratio. Furthermore, keeping crest width and submergence ratios constant, solitary waves with higher initial heights are simulated. Results of simulation indicate that transmission coefficient becomes higher for the same breakwater characteristics. Finally, a parametric study is conducted on the effect of side slopes of breakwaters. It is shown that side slopes have strong effect on wave transmission.
\end{abstract}

\section{Introduction}

Submerged breakwaters are the most widely used of numerous methods for protecting harbors and coastlines from destructive effects of waves and currents. Therefore, meticulous design is necessary to obtain the best performance and effectiveness according to waves and environmental characteristics of subjected area. To obtain the best design, having a good notion of the effect of different parameters of breakwaters on different waves is crucial. For examining the performance of breakwater, many aspects of these structures have to be considered such as geometry, permeability, and erosion, with geometry being the most important among them. Many scientific and engineering investigations have been conducted on these types of structures since their appearance.
Examination of behavior of different types of breakwaters to obtain reflection and transmission characteristics has been the subject of many studies. For example, Sabuncu and Goren [1] studied propagation of wave over sloping seabed and also over impermeable submerged breakwaters and examined its transmission and reflection characteristics. In another work, Stamos and Hajj [2], by studying the flexible and rigid breakwaters, obtained transmission and reflection characteristics for various wave steepness with different internal pressures. Also, they proposed optimal widths for breakwaters with different wave lengths. Lin and Liu [3] obtained an analytical solution for reflection of wave from a rectangular obstacle. Another important work in this regard is the investigation carried out by $\mathrm{K} . \mathrm{H}$. Chen and J. T. Chen [4] in which transmission and reflection coefficients were obtained by propagating oblique incident wave over 
a breakwater. Hsiao et al. [5] also mathematically investigated reflection characteristics of composite breakwaters in facing incident waves. Lee and Mizutani [6] experimentally studied front local scour of submerged impermeable breakwater and presented a new method of estimation for evaluating scour depth. Also, Dhinakaran et al. [7] studied effect of hydrodynamic characteristics such as transmission and reflection coefficients, dimensionless forces, and pressures on the semicircular caisson for different water depths. Same authors [8] later investigated hydrodynamic performance of semicircular breakwaters under submerged condition. They considered effectiveness of different parameters on semicircular breakwaters hydrodynamic performance such as vertical forces, horizontal forces, dimensionless pressures, and characteristics of transmission and reflection. Kriezi and Karambas [9] considered submerged rectangular breakwater and obtained reflection and transmission characteristics both numerically and experimentally. Jung et al. [10] investigated reflection of both regular and irregular waves for vertical and slit caissons with porous structures. Recently, Wen et al. [11] investigated affectivity and feasibility of Bragg type breakwaters on increasing wave energy, by using equation model of Hybrid Mild-Slope. On the other hand, Jabbari et al. [12] and Ghadimi et al. [13], by applying extended Boussinesq equations, studied transmission of periodic wave over submerged breakwaters and sloping and barred beaches.

In recent years, there have been many attempts to study and simulate solitary waves using different types of water equations [14, 15]. In 2012, Zhang et al. [16] studied propagation of solitary wave interacting with permeable submerged breakwater and assessed effectiveness of different parameters on solitary wave characteristics. Also, Jabbari and Ghadimi [17] numerically studied the interaction of solitary waves and submerged breakwaters with sharp vertical edges.

Up until now, there has been much attention given to computing transmission coefficient for various types of waves propagating over submerged breakwaters. However, there does not appear to be sufficient investigation about obtaining transmission coefficients in propagation of solitary waves over submerged trapezoidal breakwater using extended Boussinesq equations. For this reason, in the current study, transmission characteristics of trapezoidal breakwaters are investigated using Madsen and Sorensen extended Boussinesq equations. Also, parametric studies are conducted to examine the effect of different influential factors such as configuration and side slopes of symmetric and asymmetric breakwaters and initial wave height.

\section{Problem Formulation}

Simulation of wave interacting with submerged breakwater is accomplished by applying Madsen and Sorensen extended Boussinesq equations consisting of continuity and momentum as in

$$
\frac{\partial \eta}{\partial t}+\frac{\partial Q}{\partial x}=0
$$

$$
\begin{aligned}
\frac{\partial Q}{\partial t}+ & \frac{\partial}{\partial x}\left(\frac{Q^{2}}{d}\right)+g d \frac{\partial \eta}{\partial x} \\
= & \left(B+\frac{1}{3}\right) h^{2} \frac{\partial}{\partial x}\left(\frac{\partial^{2} Q}{\partial x \partial t}\right)+B g h^{3} \frac{\partial}{\partial x}\left(\frac{\partial^{2} \eta}{\partial x^{2}}\right) \\
& +h h_{x}\left(\frac{1}{3} \frac{\partial^{2} Q}{\partial x \partial t}+2 B g h \frac{\partial^{2} \eta}{\partial x^{2}}\right),
\end{aligned}
$$

where $h(x)$ is still water depth, $g$ is gravity acceleration, and $d$ is defined as $d=h+\eta$, wih $\eta$ being water surface level. Here, $Q$ denotes depth-integrated velocity component and $B$ is dispersion coefficient. In this study, based on the work of Madsen and Sørensen [18], a value 1/15 is considered for $B$. Also, subscript $x$ indicates partial differentiation in space.

\section{Numerical Method}

3.1. Finite Element Modeling of Galerkin. Discretization of governing equations is done using Galerkin finite element method. Computational domain is divided into small regions and solution is approximated over each subregion by a simple function. Approximation of dependent variables by finite element method is presented in

$$
f \approx \sum_{i=1}^{n d} N_{i} f_{i},
$$

where $f_{i}$ is the nodal value of dependent variables and $N_{i}$ is the standard basis function.

3.2. Solution Formulation. Final forms of governing equations for simulation purposes are presented in (3) through (5):

$$
\begin{gathered}
\frac{\partial \eta}{\partial t}+\frac{\partial Q}{\partial x}=0, \\
\frac{\partial Q}{\partial t}+\frac{\partial}{\partial x}\left(\frac{Q^{2}}{d}\right)+g d \frac{\partial \eta}{\partial x} \\
=\left(B+\frac{1}{3}\right) h^{2} \frac{\partial}{\partial x}\left(\frac{\partial^{2} Q}{\partial x \partial t}\right)+B g h^{3}\left(\frac{\partial^{2} w}{\partial x^{2}}\right) \\
+h h_{x}\left(\frac{1}{3} \frac{\partial^{2} Q}{\partial x \partial t}+2 B g h \frac{\partial^{2} \eta}{\partial x^{2}}\right), \\
w=\frac{\partial \eta}{\partial x} .
\end{gathered}
$$

Numerical scheme, dealing with an auxiliary equation for modeling Madsen and Sorensen's Boussinesq equations, has been outlined in an earlier work by the present authors [13].

3.3. Spatial Discretization. Using Galerkin finite element method, discretized form of continuity equation is as follows:

$$
\int N_{k}\left[\frac{\partial \eta}{\partial t}+\frac{\partial Q}{\partial x}\right] d \Omega^{\theta}=0
$$


Matrix form continuity equation for each element is

$$
M_{k i} \dot{\eta}_{i}+T_{k i} Q_{i}=0
$$

where

$$
\begin{aligned}
& M_{k i}=\int N_{k} N_{i} d \Omega^{\theta}, \\
& T_{k i}=\int N_{k} \frac{\partial N_{i}}{\partial x} d \Omega^{\theta} .
\end{aligned}
$$

Discretized form of momentum and auxiliary equations are also given as

$$
\begin{gathered}
{\left[M_{k i}+\left(B+\frac{1}{3}\right) h E_{k i}-\frac{1}{3} h h_{x} T_{k i}\right] \dot{Q}} \\
+T_{k i}\left(\frac{Q^{2}}{d}\right)_{i}+B g h^{2} E_{k i} w_{i} \\
+\left[2 B g h h_{x} E_{k i}+g P_{k i j} d_{j}\right] \eta_{i}=0 \\
M_{k i} w_{i}=T_{k i} \eta_{i},
\end{gathered}
$$

where

$$
\begin{aligned}
P_{k i j} & =\int N_{k} N_{i} \frac{\partial N_{j}}{\partial x} d \Omega^{\theta} \\
E_{k i} & =\int h \frac{\partial N_{k}}{\partial x} \frac{\partial N_{i}}{\partial x} d \Omega^{\theta}-S A_{k i} \\
S A_{k i} & =\int h N_{k} \frac{\partial N_{i}}{\partial x} \cdot n_{x} d \Gamma^{\theta}
\end{aligned}
$$

in which, $\Gamma^{\theta}$ represents boundary of the element with unit normal $n$. Boundary integrals are eliminated for Dirichlet boundary conditions.

3.4. Time Discretization. For time integration purposes, Adams-Bashforth-Moulton predictor-corrector method is used. Global matrix resulting from discretization of continuity and momentum is written as

$$
[M]\{\dot{f}\}=E .
$$

At the predictor step, the value of dependent variables can be obtained using

$$
[M]\{f\}^{n+1}=[M]\{f\}^{n}+\frac{\Delta t}{12}\left[23\{E\}^{n}-16\{E\}^{n-1}+5\{E\}^{n-2}\right] .
$$

Later, a fourth-order Adams-Moulton scheme is used to compute final values of the variables at the corrector step, which is calculated from the predictor step. Consider

$$
\begin{aligned}
{[M]\{f\}^{n+1}=} & {[M]\{f\}^{n} } \\
& +\frac{\Delta t}{24}\left[9\{E\}^{n+1}+19\{E\}^{n}-5\{E\}^{n-1}+\{E\}^{n-2}\right]
\end{aligned}
$$

3.5. Wave Absorbing Boundary Conditions. Damping of the waves can be done through different numerical techniqes which permits waves to exit the computational domain without any reflection. To accomplish this task, sponge layer proposed by Larsen and Dancy [19] is applied in the current study. Accordingly, surface elevation and fluxes are divided by a coefficient $\mu(x)$ after each time step. Therefore $\mu(x)$ takes the form of

$$
\mu(x)= \begin{cases}\exp \left[\left(2^{-d / \Delta d}-2^{-d_{s} / \Delta d}\right) \ln (\alpha)\right], & 0 \leq d \leq d_{s} \\ 1 & d_{s}<d,\end{cases}
$$

where $d$ is the distance between boundary and sponge layer, $d_{s}$ is often equal to one or two wave lengths, $\Delta d$ is the size of the element, and $\alpha$ is a specified constant. The prescribed value of $\alpha$ in the present work is $\alpha=4$.

3.6. The Transmission Coefficient. Breakwaters are designed to protect harbors and coastal regions against waves by reducing wave energies. Efficiency of these structures can be measured by wave transmission coefficient which is defined as

$$
C_{t}=\frac{H_{t}}{H_{i}}
$$

where $C_{t}$ is wave transmission coefficient, $H_{i}$ is initial wave height, and $H_{t}$ is height of transmitted wave over structure. In this work, in order to measure these wave heights, two gauges are considered in the computational domain. First gauge is located at 9.0 meter before the breakwater's seaward slope and the second gauge is located at 6.0 meter after breakwater in its lee side.

\section{Numerical Simulations}

4.1. Configuration Effect of Submerged Breakwater on Transmission Coefficient. In this test case, the most important parameters in controlling the effectiveness of submerged breakwaters such as crest width ratio, submergence ratio, and initial wave height are considered. Here, submergence ratio is defined as $h / d$ and crest width ratio is defined as $W / d$.

To achieve this goal, numerical domain is considered $40.0 \mathrm{~m}$ long and is discretized into 400 elements with a mesh size $\Delta x=0.1 \mathrm{~m}$. Water depth $(h)$ is $1.0 \mathrm{~m}$. Time step is considered fixed and equal to $0.005 \mathrm{~s}$. Slope of both sides of breakwater (with $0.8 \mathrm{~m}$ height) is $1: 2$. Also, sponge layer is considered at the right hand of computational domain. Five different values are considered for the crest width ratio including $0.0,0.4,0.8,1.2$, and 1.6. Also, eight different values are considered for submergence ratio including $0.3,0.4,0.5$, $0.6,0.7,0.8$, and 0.85 . Definition of the related parameters is illustrated in Figure 1.

Figure 2 shows the effect of both submergence ratio and crest width ratio on transmission coefficient. As seen in the figure, for higher values of submergence ratio, transmission coefficient decreases. Similar behavior can be detected for higher values of crest width ratio. In Figure 3, it is evident that, 


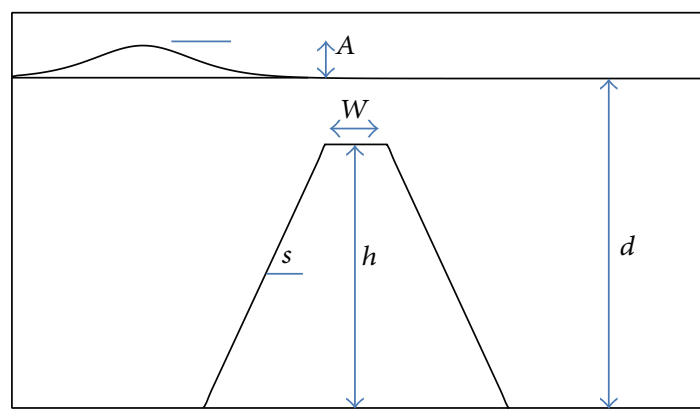

FIgURE 1: Computational domain.

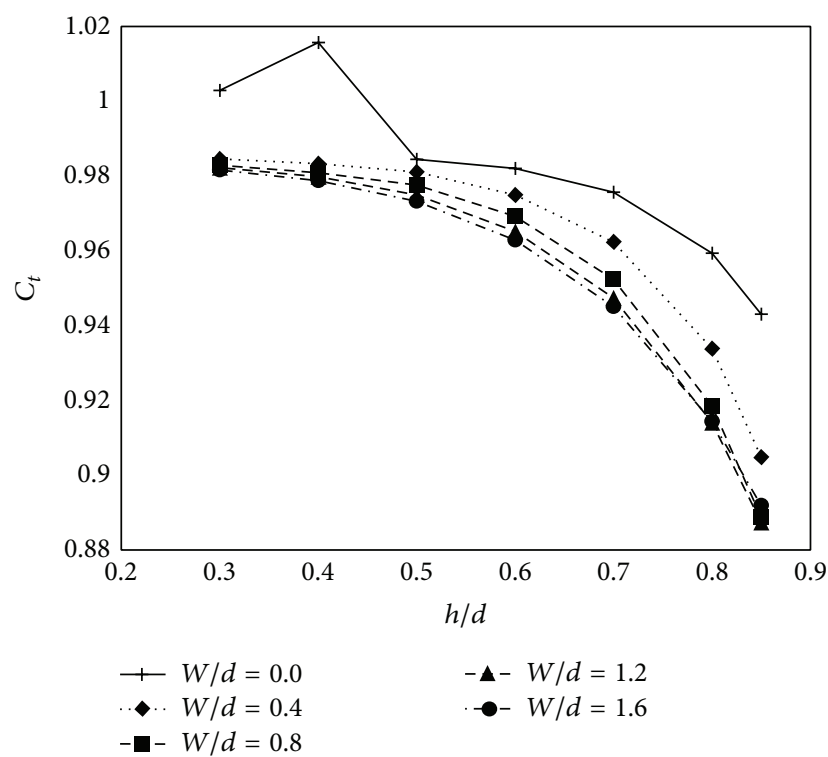

Figure 2: Comparison of transmission coefficient obtained for a wave with $A=0.06$.

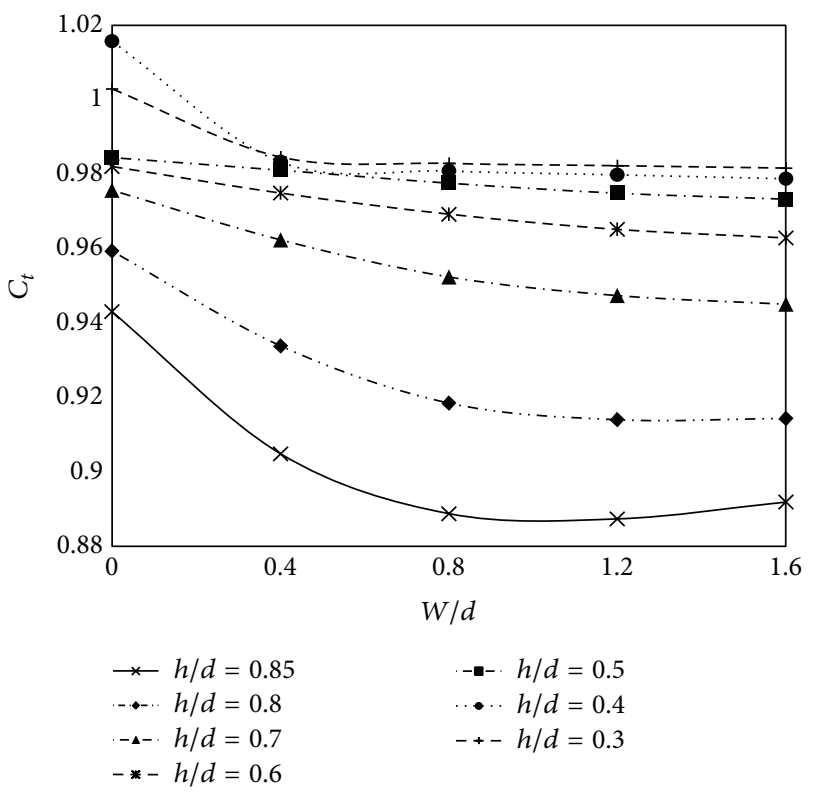

FIGURE 3: Comparison of transmission coefficients obtained for a wave with $A=0.06$.

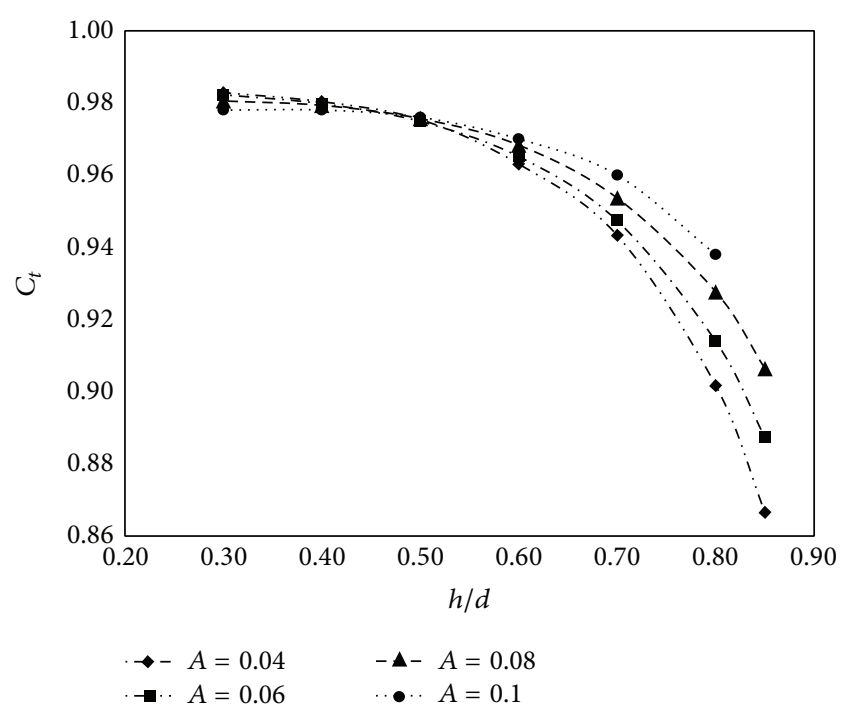

FIgURE 4: Comparison of transmission coefficients obtained for a wave of $W / d=1.2$ and initial height ranging from 0.04 to 0.1 .

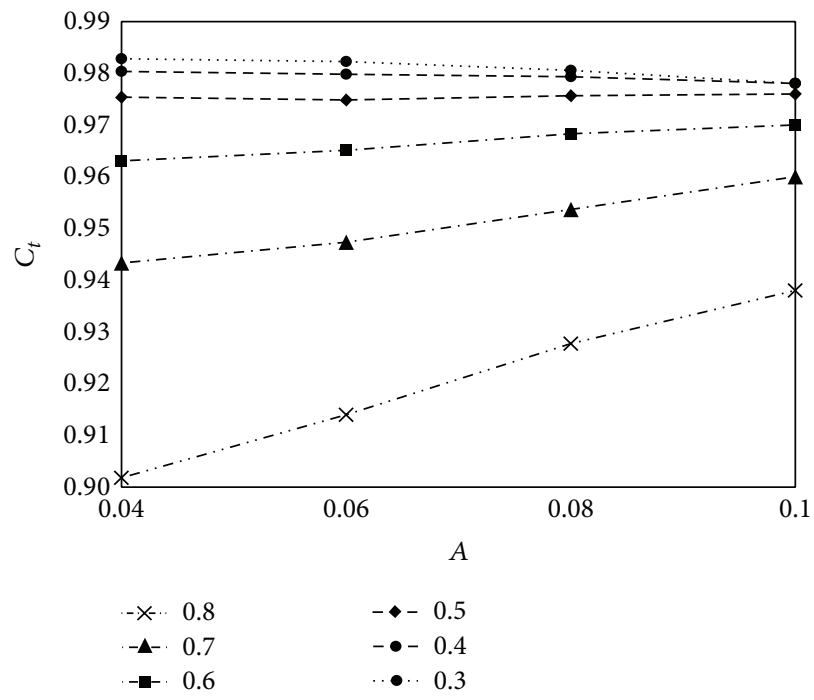

Figure 5: Comparison of transmission coefficients obtained for a wave of $W / d=1.2$ and initial height ranging from 0.3 to 0.8 .

as crest width ratio increases from 0.0 to 0.8 , transmission coefficient significantly decreases for all values of submergence ratio whereas, for higher values than 0.8 , transmission coefficient slightly decreases.

4.2. Assessment of Effectiveness of Initial Wave Height on Transmission Coefficient. In this test case, previous domain is used again for simulation and effectiveness of initial solitary wave heights propagating over a submerged breakwater on transmission coefficient is investigated. Accordingly, four different waves with amplitudes $0.04,0.06,0.08$, and 0.1 are propagated over a submerged breakwater with a crest width ratio of $1.2 \mathrm{~m}$ and submergence ratio of 0.3 to 0.85 . Computed results are illustrated in Figures 4 and 5. 


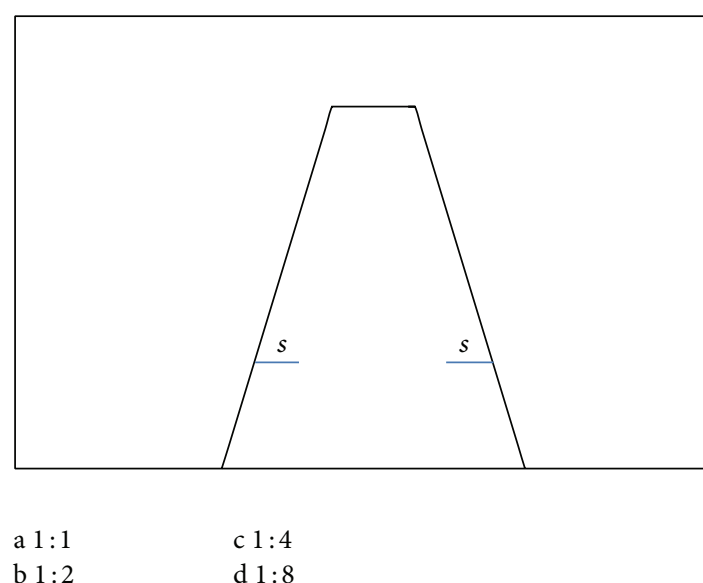

(a)

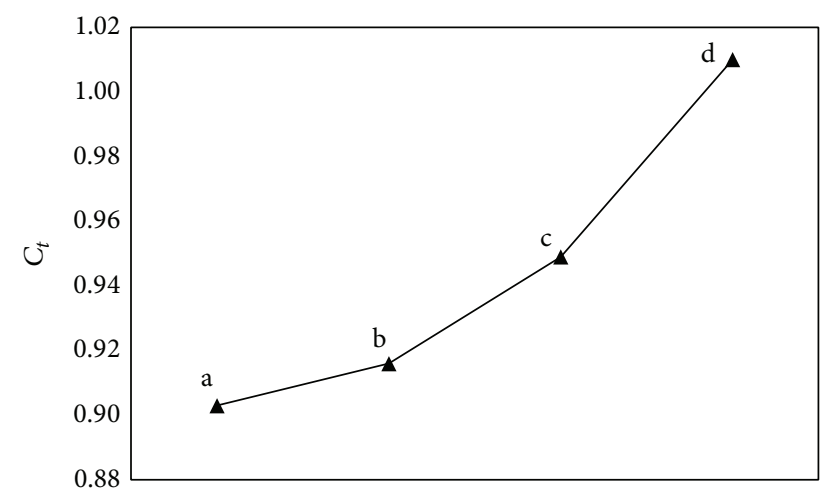

(b)

FIGURE 6: Comparison of transmission coefficients obtained for wave with $W / d=1.2, h / d=0.8$, and $A=0.06$. (a) Geometry of breakwater and (b) computed transmission coefficient.

Computed results in Figures 4 and 5 indicate that by increasing the initial solitary wave height, transmission coefficient decreases. In other words, loss of energy in solitary waves with lower wave heights is more than that with higher wave heights.

4.3. Assessment of Symmetric Side Slopes on Transmission Coefficient. In order to assess effectiveness of symmetric side slopes on transmission coefficient, a solitary wave of initial wave height 0.06 is propagated over a submerged breakwater with height of 0.8 and crest width ratio of 1.2 and four different symmetric side slopes of $1: 1,1: 2,1: 4$, and $1: 8$. Related results are illustrated in Figure 6.

As illustrated in Figure 6, by increasing both side slopes of symmetric breakwater, transmission coefficient increases and for breakwater with both side slopes of $1: 8$, both initial and transmitted wave heights are almost equal.

4.4. Assessment of Asymmetric Side Slope on Transmission Coefficient. In this test, effect of asymmetric side slopes on tranmission coefficient is considered in two different modes. To achieve this goal at first mode, front side slope of
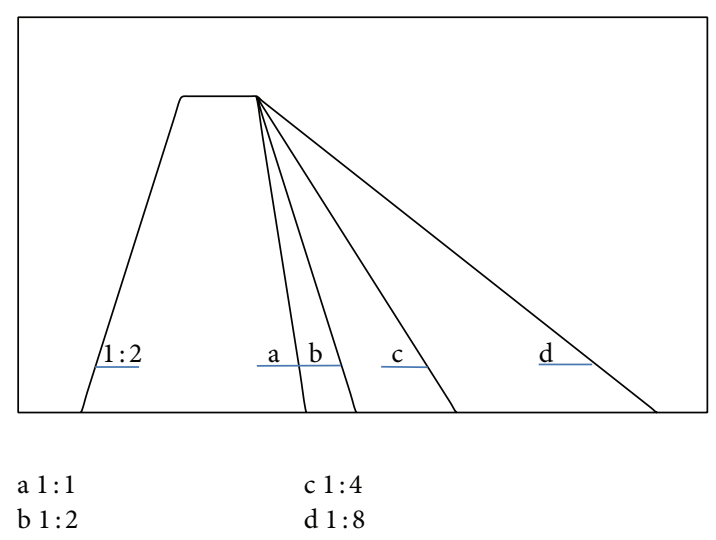

(a)

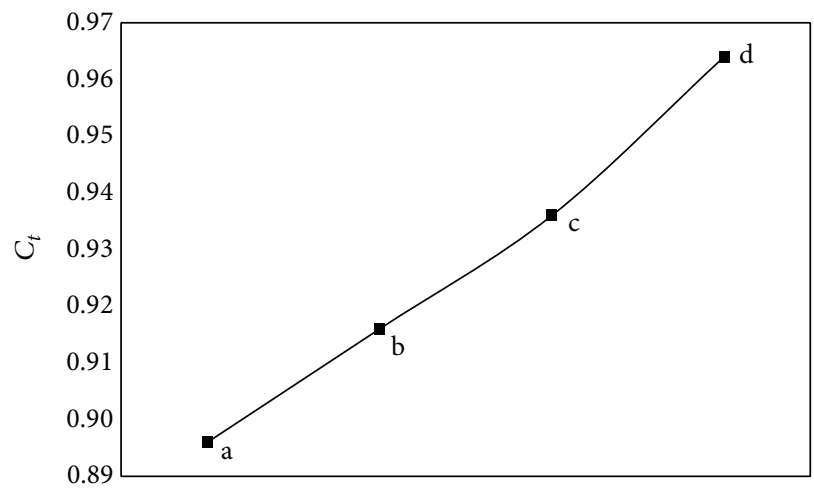

(b)

FIGURE 7: Comparison of transmission coefficient obtained for wave with $W / d=1.2, h / d=0.8$, and $A=0.06$. (a) Geometry of breakwater and (b) computed transmission coefficient.

breakwater is considered to be constant at $1: 2$ and four different side slopes of $1: 1,1: 2,1: 4$, and $1: 8$ for back side slope are selected. In second mode, this procedure is repeated with keeping back side slope constant and varying front side slopes. The measured transmission coefficients for both modes are plotted in Figures 7 and 8.

As evident in Figure 7, transmitted coefficient increases for higher degree of back side slope of breakwater, but this process is slightly different for different front side slopes in Figure 8, where transmission coefficient decreases for front side slope of $1: 1$ to $1: 2$ and subsequently transmission coefficient increases by an increase in side slope.

\section{Conclusions}

In this study, investigation of transmission coefficients of propagating solitary waves over submerged breakwaters of various configurations has been accomplished. Galerkin finite element method is used for spatial discretization, while Adams-Bashforth-Moulton predictor-corrector method is considered for time integration. Effectiveness of breakwater is investigated by introducing two parameters: submergence ratio and crest width ratio. Eight different values of submergence ratio ranging from 0.3 to 0.85 and five different values 

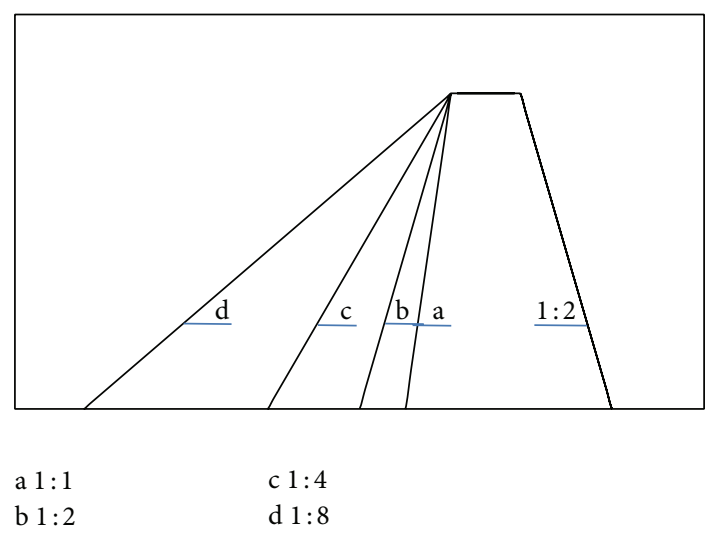

(a)

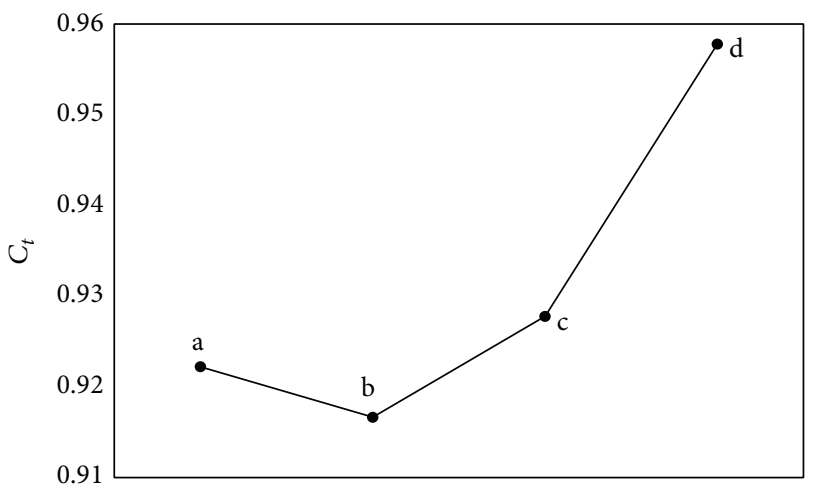

(b)

FIGURE 8: Comparison of transmission coefficient obtained for wave with $W / d=1.2, h / d=0.8$, and $A=0.06$. (a) Geometry of breakwater and (b) computed transmission coefficient.

of crest width ratio ranging from 0.0 to 1.6 are considered. It is established through a number of test cases that the lowest transmission coefficient relates to breakwater with submergence ratio of 0.85 and crest width ratio of 1.2 . Subsequently, effectiveness of initial height of solitary wave is investigated. It is shown that a solitary wave with lower initial height has lower transmission coefficient compared to higher wave heights. Finally, effectiveness of side slopes is investigated for both symmetric and asymmetric breakwaters and among different values of side slopes considered, the lowest transmission coefficient is obtained for breakwater with slopes of $1: 2$ and 1:1 for both front and back side. This is indicative of the fact that side slopes have strong effect on wave transmission.

\section{Conflict of Interests}

The authors declare that there is no conflict of interests regarding the publication of this paper.

\section{References}

[1] T. Sabuncu and O. Goren, "Wave propagation over sloping bottom and submerged breakwaters," in Marina Technology, pp. 185-195, ICE, Westminster, London, 1992.
[2] D. G. Stamos and M. R. Hajj, "Reflection and transmission of waves over submerged breakwaters," Journal of Engineering Mechanics, vol. 127, no. 2, pp. 99-105, 2001.

[3] P. Lin and H.-W. Liu, "Analytical study of linear long-wave reflection by a two-dimensional obstacle of general trapezoidal shape," Journal of Engineering Mechanics, vol. 131, no. 8, pp. 822830, 2005.

[4] K. H. Chen and J. T. Chen, "Adaptive dual boundary element method for solving oblique incident wave passing a submerged breakwater," Computer Methods in Applied Mechanics and Engineering, vol. 196, no. 1-3, pp. 551-565, 2006.

[5] S.-S. Hsiao, H.-M. Fang, J. Chang, and J.-R. Chang, "Investigations on wave reflection characteristics due to composite breakwater," International Journal of Offshore and Polar Engineering, vol. 17, no. 2, pp. 112-118, 2007.

[6] K.-H. Lee and N. Mizutani, "Experimental study on scour occurring at a vertical impermeable submerged breakwater," Applied Ocean Research, vol. 30, no. 2, pp. 92-99, 2008.

[7] G. Dhinakaran, V. Sundar, R. Sundaravadivelu, and K. U. Graw, "Regular wave measurements on a submerged semicircular breakwater," Journal of Offshore Mechanics and Arctic Engineering, vol. 132, no. 3, pp. 1-6, 2010.

[8] G. Dhinakaran, V. Sundar, R. Sundaravadivelu, and K. U. Graw, "Performance of a perforated submerged semicircular breakwater due to non-breaking waves," Journal of Engineering for the Maritime Environment, vol. 226, no. 1, pp. 36-50, 2012.

[9] E. Kriezi and T. Karambas, "Modelling wave deformation due to submerged breakwaters," Proceedings of the Institution of Civil Engineers: Maritime Engineering, vol. 163, no. 1, pp. 19-29, 2010.

[10] T. H. Jung, S. J. Lee, and Y. S. Cho, "Characteristics of wave reflection for vertical and slit caissons with porous structures," Journal of Applied Mathematics, vol. 2012, Article ID 972650, 15 pages, 2012.

[11] C. C. Wen, T. L. Lee, C. L. Chen, and Y. J. Lin, "The feasibility and effectiveness of using Bragg breakwaters in the shoreline wave climate for east Taiwan ocean energy," The Open Civil Engineering Journal, vol. 7, pp. 101-108, 2013.

[12] M. H. Jabbari, P. Ghadimi, M. Sayehbani, and A. Reisinezhad, "A unique finite element modeling of the periodic wave transformation over sloping and barred beaches by Beji and Nadaoka's extended Boussinesq equations," The Scientific World Journal, vol. 2013, Article ID 306535, 11 pages, 2013.

[13] P. Ghadimi, A. Rahimzadeh, M. H. Jabbari, and R. Zamanian, "Finite element modeling of regular waves by 1-D Madsen and Sorensen extended Boussineq equations," American Journal of Marine Science, vol. 1, no. 1, pp. 1-6, 2013.

[14] J. Zhou and L. Tian, "Periodic and solitary-wave solutions for a variant of the $K(3,2)$ equation," International Journal of Differential Equations, vol. 2011, Article ID 582512, 16 pages, 2011.

[15] B. Kiliç and B. Bulut, "A new method with a different auxiliary equation to obtain solitary wave solutions for nonlinear partial differential equations," Advances in Mathematical Physics, vol. 2013, Article ID 890784, 11 pages, 2013.

[16] J. Zhang, J. Zheng, D. S. Jeng, and G. Wang, "Numerical simulation of solitary wave induced flow motion around a permeable submerged breakwater," Journal of Applied Mathematics, vol. 2012, Article ID 508754, 14 pages, 2012. 
[17] M. H. Jabbari, P. Ghadimi, A. Masoudi, and M. R. Baradaran, "Numerical modeling of the interaction of solitary waves and submerged breakwaters with sharp vertical edges using onedimensional Beji \& Nadaoka extended Boussinesq equations," International Journal of Oceanography, vol. 2013, Article ID 691767, 7 pages, 2013.

[18] P. A. Madsen and O. R. Sørensen, "A new form of the Boussinesq equations with improved linear dispersion characteristics. Part 2. A slowly-varying bathymetry," Coastal Engineering, vol. 18, no. 3-4, pp. 183-204, 1992.

[19] J. Larsen and H. Dancy, "Open boundaries in short wave simulations-a new approach," Coastal Engineering, vol. 7, no. 3, pp. 285-297, 1983. 

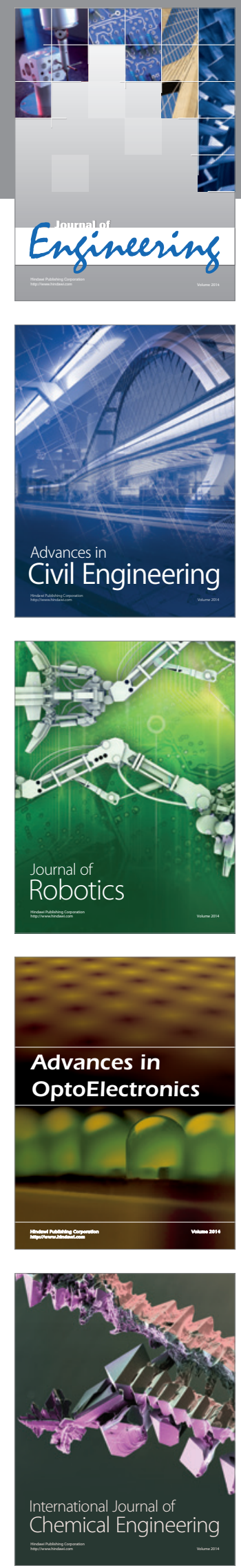

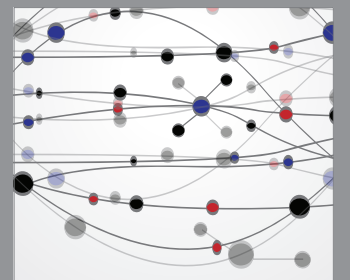

The Scientific World Journal
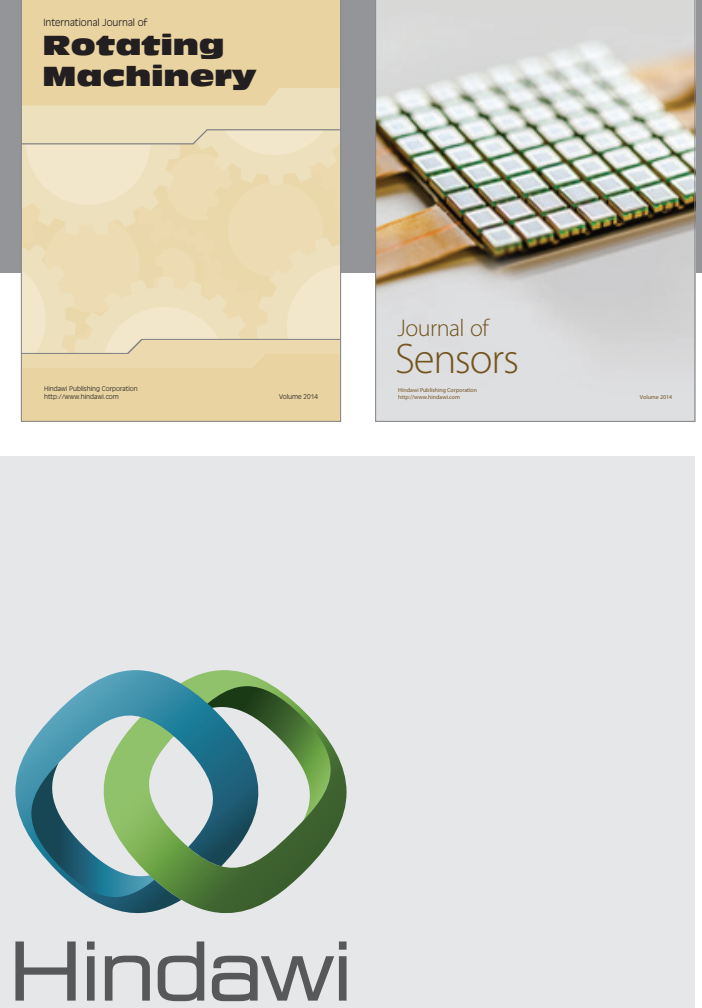

Submit your manuscripts at http://www.hindawi.com
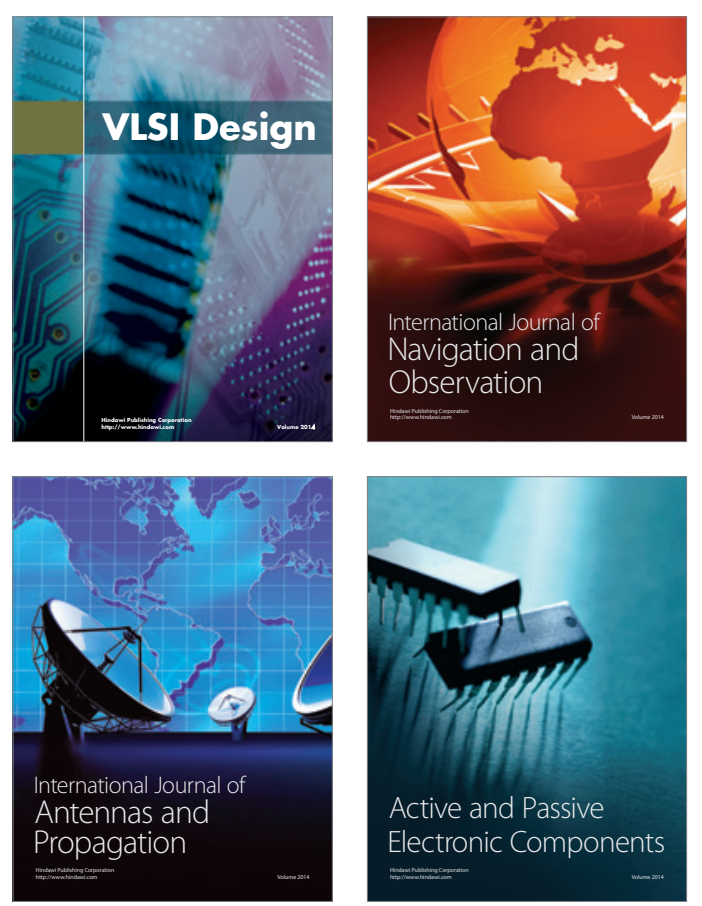
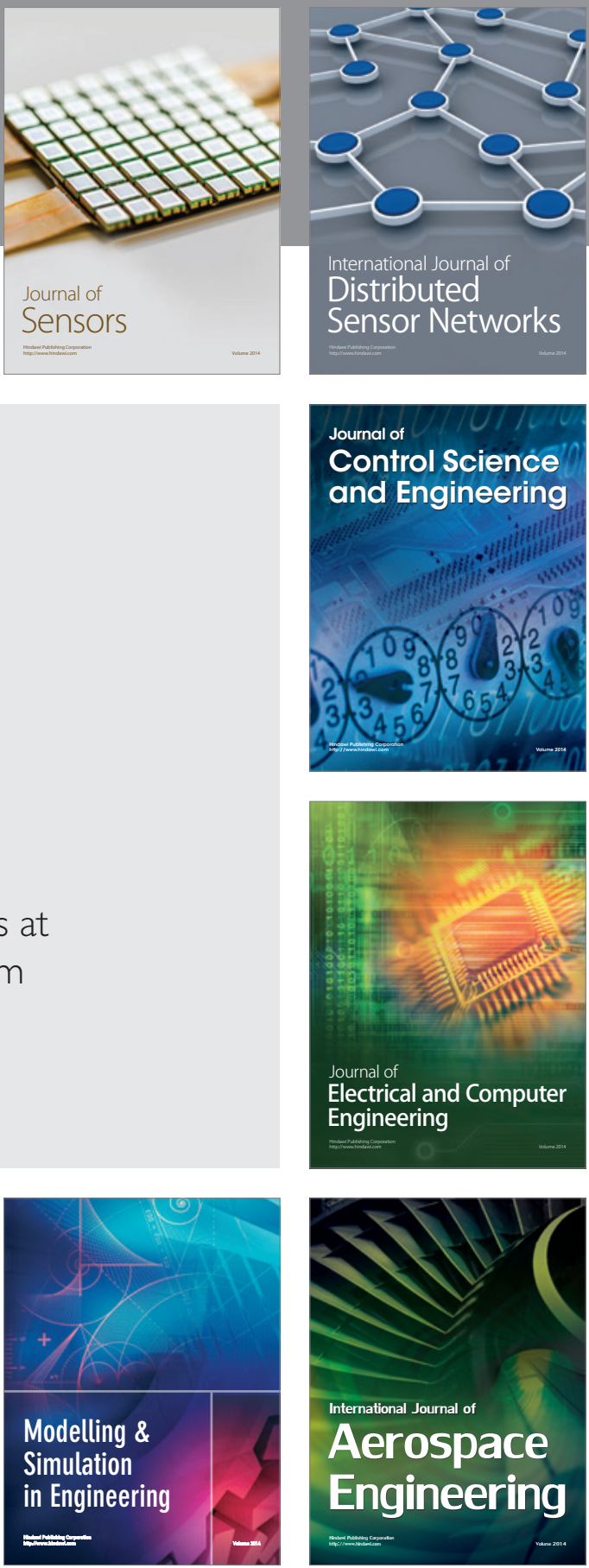

Journal of

Control Science

and Engineering
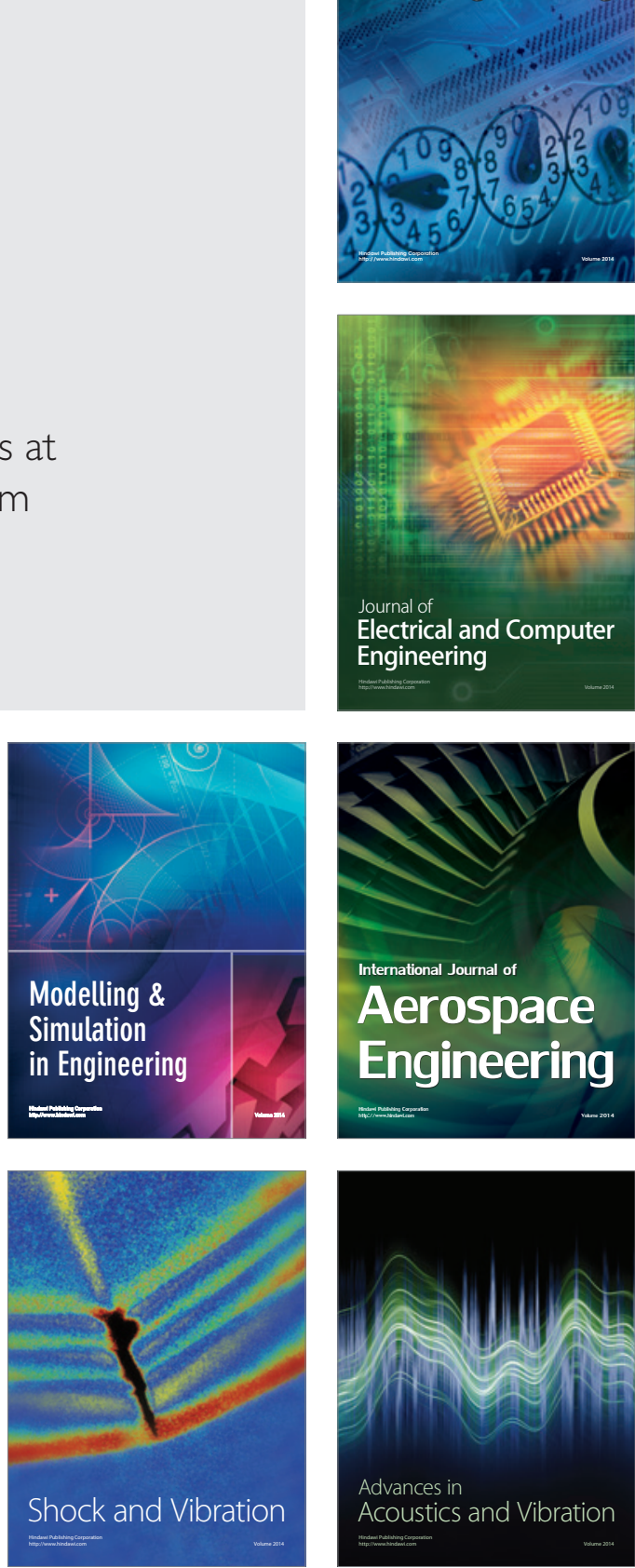